Results A total of 6336 tests were performed of which 4454 (70.1\%) were negative for paracetamol. The Table 1 shows the number of tests by year and result. Using the Chi Squared test there were no significant differences before and after September $1998(\mathrm{p}=0.7)$.

\begin{tabular}{llllll}
\multicolumn{5}{l}{ Abstract SAT0243 } & Table 1 \\
\hline & $95 / 96$ & $96 / 97$ & $97 / 98$ & $98 / 99$ & $99 / 00$ \\
\hline All Tests & 1063 & 1380 & 1365 & 1182 & 1346 \\
All Positive Tests & 319 & 362 & 403 & 358 & 440 \\
Results $>1.3 \mathrm{mmol} / \mathrm{I}$ & 23 & 27 & 27 & 27 & 28 \\
\hline
\end{tabular}

Conclusion These results do not suggest that the incidence of paracetamol overdose has been affected by the over-the-counter pack size reduction at least in the Tayside region of Scotland. Further measures to reduce the burden of paracetamol overdose to the healthcare system must be considered along with effective ways of obtaining paracetamol for appropriate clinical use.

\section{SAT0244 CONCOMITANT USE OF GASTROPROTECTIVE AGENTS AMONG USERS OF NONSTEROIDAL ANTIINFLAMMATORY DRUGS IN ITALY}

${ }^{1}$ AP Caputi, ${ }^{2}$ SX Kong, ${ }^{2} \mathrm{P}$ Mavros, ${ }^{3} \mathrm{E}$ Ricci, ${ }^{1} \mathrm{~A}$ Russo. 'Institute of Pharmacology, University of Messina, Messina, Italy; ${ }^{2}$ Outcomes Research, Merck \& Co., Inc., Whitehouse Station, NJ, USA; ${ }^{3}$ Center of Health Economics, Institute Di Ricerche Farmacologiche, Ranica, Italy

\subsection{6/annrheumdis-2001.880}

Background Beside life-threatening gastrointestinal (GI) adverse events (e.g. perforation, ulcer or bleeding), non-steroidal antiinflammatory drug (NSAID) use is associated with less severe GI symptoms, which may result in the concurrent use of GI protective agents (GPAs) and/or antacids and therefore increased medical costs.

Objectives Analyse the patterns of use of GI protective agents among NSAID users.

Methods During ten days of consultation, 913 NSAID users were identified among 20,668 patients seen by 103 general practitioners in the Sicily region of Italy from December 1998 to June 1999. Physicians filled out data collection forms regarding the type and indication of NSAIDs and the use of adjuvant therapy to prevent or treat adverse GI effects of NSAID therapy during the past 6 months.

Results The mean age of the patients was 61 years and $61 \%$ were females. Indications for NSAID therapy included osteoarthritis/arthrosis in $61 \%$ of the patients, rheumatoid arthritis in $9 \%$, and other reasons, most notably non-articular pain in $28 \%$. Based on the number of prescriptions $(\mathrm{Rx})$ and the number of patients (pts), the most frequently prescribed NSAID was nimesulide (24\% Rx, 37\% pts), followed by diclofenac (24\% Rx, $32 \% \mathrm{pts})$, piroxicam (17\% Rx, 24\% pts), and ketoprofen $(9 \%$ $\mathrm{Rx}, 12 \% \mathrm{pts})$ accounting for $75 \%$ of all NSAID prescriptions. The mean duration of all NSAID therapy varied between 60 to 120 days depending on the specific NSAIDs used by the patients during the 6 months prior to the visit. Of all NSAID users, $50.3 \%$ used a GI medication, including GPAs [including proton pump inhibitors (PPI), H2-antagonists, and misoprostol] and antacids (Rx or OTC). Although certain variations existed, the use of GPAs and antacids was consistent across all NSAIDs including those newer products such as ArthrotecÒ and meloxicam.
Concomitant use of $\mathrm{H} 2$-antagonists occurred in $14 \%$ of all NSAID users, PPI in $8 \%$, misoprostol in $15 \%$, and antacids in 22\%. The mean duration of GPA use varied between 73 to 96 days during the 6 -month period. About $40 \%$ of $\mathrm{H} 2$ antagonists, $21 \%$ PPI, $86 \%$ misoprostol, and $62 \%$ antacids were prescribed to prevent NSAID adverse events and the remaining were for treatment.

Conclusion Concurrent use of gastroprotective agents and antacids was observed in more than half of the patients taking NSAIDs, and their use was consistent across individual products. The concomitant use of GPAs and/or antacids with NSAIDs does not only incur inconvenience to the patients because of polypharmacy but also increase healthcare costs.

\section{SAT0245 IMPROVEMENT IN HEALTH-RELATED QUALITY OF LIFE FROM ANAKINRA THERAPY IN PATIENTS WITH RHEUMATOID ARTHRITIS NOT USING DMARDS}

${ }^{1} \mathrm{P}$ Emery, ${ }^{2} \mathrm{JM}$ Woolley, ${ }^{2} \mathrm{WW}$ Chan. ${ }^{1}$ Rheumatology and Rehabilitation Research Unit, University of Leeds, Leeds, UK; ${ }^{2}$ Amgen Inc., Thousand Oaks, USA

10.1136/annrheumdis-2001.881

\section{Background}

Objectives To evaluate the effect of anakinra on health related quality of life (HRQOL) as measured by the Nottingham Health Profile (NHP), in subjects with rheumatoid arthritis not using DMARDs.

Methods In a 24-week, multicenter, randomised, double-blind clinical trial conducted in Europe, 473 subjects received either one of three doses of anakinra $(30 \mathrm{mg}, 75 \mathrm{mg}$, or $150 \mathrm{mg}$ ) or placebo SC QD. Subjects were excluded if they used DMARDs within six weeks of entry, or if they had failed therapy with more than three DMARDs. The NHP was administered in selected countries at baseline and at weeks 12 and $24(\mathrm{n}=353)$. The NHP consists of 38 items which assess physical mobility (MOB), pain (PAIN), energy (ENRG), sleep (SLP), emotional reactions (EMO), and social isolation (ISO). The NHP is scored so that lower scores indicate better HRQOL and negative change scores indicate improvements. The mean change in each NHP scale score was compared between subjects receiving anakinra (all doses combined) and those on placebo. All subjects who completed at least one post-baseline assessment were included (n $=328$ ) and the last-observation was carried forward in the case of missing data.

Results Subjects using anakinra experienced statistically significant improvements in all six NHP scales. These improvements exceeded those for subjects on placebo for all six scales, four of which were statistically significant.

\begin{tabular}{|c|c|c|c|c|c|c|}
\hline & МОВ & PAIN & ENRG & SLP & EMO & ISO \\
\hline Anakinra $(n=245)$ & -8.89 & -17.27 & -18.88 & -9.55 & -11.51 & -4.91 \\
\hline Placebo $(n=83)$ & 0.19 & -7.89 & -4.82 & -3.27 & -3.48 & -0.49 \\
\hline Difference & -9.08 & -9.38 & -14.06 & -6.28 & -8.03 & -4.42 \\
\hline P-Value & $<0.01$ & 0.02 & 0.01 & 0.13 & 0.01 & 0.12 \\
\hline
\end{tabular}

Conclusion Subjects receiving anakinra experienced statistically significant improvements in their NHP scores that exceeded those for subjects on placebo. These improvements were seen in 